\title{
Leisure time physical activity and health-related behaviours after liver transplantation: a prospective, single-centre study
}

\author{
Katarzyna Kotarskaํ, Ewa Wunsch², Joanna Raszeja-Wyszomirska, Agnieszka Kempińska-Podhorodecka4, \\ Maciej Wójcicki' ${ }^{2,3}$, Piotr Milkiewicz ${ }^{2,3}$ \\ ${ }^{1}$ Department of Physical Culture and Health Promotion, University of Szczecin, Szczecin, Poland \\ ${ }^{2}$ Department of Clinical and Molecular Biochemistry, Pomeranian Medical University, Szczecin, Poland \\ ${ }^{3}$ Hepatology and Internal Medicine Unit, Department of General, Transplant, and Liver Surgery, Medical University \\ of Warsaw, Warsaw, Poland \\ ${ }^{4}$ Medical Biology Laboratory, Pomeranian Medical University, Szczecin, Poland
}

Prz Gastroenterol 2015; 10 (2): 100-104 DOI: $10.5114 / p g .2015 .49002$

Key words: liver transplantation, Minnesota Leisure Time Physical Activity Questionnaire, health behaviour inventory.

\begin{abstract}
Address for correspondence: Piotr Milkiewicz MD, MRCP (UK), Hepatology and Internal Medicine Unit, Department of General, Transplant, and Liver Surgery, Medical University of Warsaw, 1 A Banacha St, 02-097 Warsaw, Poland, phone: +48 22599 1662, fax: +48 225991663 , e-mail: p.milkiewicz@wp.pl
\end{abstract}

\begin{abstract}
Introduction: Leisure time physical activity is of proven significance in surveys of fitness levels in various patient groups. Low physical functioning may affect recovery after liver transplantation (LTx).

Aim: To assess patients' leisure time activity and health-related habits after transplantation.

Material and methods: One hundred and seven patients after LTx were included. They were divided into groups depending on aetiology of liver problem and the period after LTX. Minnesota Leisure Time Physical Activity Questionnaire (MILTPAQ) and Health Behaviour Inventory (HBI) were applied.

Results: Neither the primary indication for the procedure nor the period after surgery had a significant relationship with physical activity assessed with MILTPAQ; however, activity was lower in females than males (1804.3 \pm 1848.9 vs. $2619.9 \pm 2067$; $p=0.03)$. Age at survey/surgery was inversely associated with higher activity $(p=0.02$ and $p=0.03$, respectively). Health Behaviour Inventory analysis showed a correlation between all four of its domains and age at transplantation/survey $(p<0.001$ for both). There was a negative correlation between positive mental attitude and body mass index (BMI).

Conclusions: The primary indications for grafting and, surprisingly, the period after surgery did not seem to be related to the patients' physical activity in leisure time. Younger and leaner patients appeared to understand the standards of healthy behaviour better and implement them in their daily activities. As higher BMI are associated with a negative mental attitude in patients after LTx, a particular emphasis should be placed on proper counselling in this subgroup of patients.
\end{abstract}

\section{Introduction}

Decreased physical activity has been demonstrated in various studies analysing patients after transplantation, and it was found to be related to various factors including employment status [1, 2] or health-related quality of life [2-5]. Patients who underwent liver transplantation (LTX) frequently complained of a variety of symptoms [4-6], leading to significant restrictions in physical activity and functioning. The Minnesota Lei- sure Time Physical Activity Questionnaire (MILTPAQ) was introduced for the first time in 1978 [7] and has been subsequently used in numerous studies, indicating its usefulness as a tool for measuring patients' activities not related to their work. The Health Behaviour Inventory is a questionnaire assessing the approach of an individual to various behaviours considered supportive to a healthy way of life [8]. It has been applied in studies on pregnant women, patients with back pain, overweight individuals, and on other groups [8-11]. 
Aim

The aim of his study was to assess the leisure time activity and health-related habits of patients who had undergone LTX in our centre.

\section{Material and methods}

One hundred and seven (62 male/45 female, range: $21-67$ years, median age 52 years) consecutive post-transplant patients who were reviewed in the outpatient clinic were included. Demographic data on analysed subjects is summarised in Table I. Indications for LTx included the following aetiologies: alcoholic $(n=24)$, viral $(n=15)$, autoimmune/cholestatic $(n=33)$, and other aetiologies $(n=35)$, respectively. They were also divided into three groups depending on the period after LTx: 6-12 months (group A); 13-36 months (group B); and over 36 months (group C).

\section{Minnesota Leisure Time Physical Activity Questionnaire (MILTPAQ)}

This questionnaire collects information on free time physical activity, providing a value of energy expenditure in kcal/week. Minnesota Leisure Time Physical Activity Questionnaire comprises a list of 63 sport, recreational, yard, and household activities. The participant is instructed to report whether or not they have performed each activity in the last 12 months [7]. One hundred and five (61 male/44 female) post-transplant patients completed MILTPAQ.

\section{Health Behaviour Inventory (HBI)}

The $\mathrm{HBI}$ contains 24 questions to evaluate health behaviour in four domains, which include nutrition habits, preventive behaviour, health practices, and mental attitude. Values selected by the tested individual are summed up to obtain an overall intensity of health behaviour in the range 24 to 120 points. The higher the score, the greater the intensity of the declared behaviours. The overall rate is converted into standardised units and is subject to interpretation in a scale of stens (1-4 stens - low score; 5-6 stens - moderate score; 7-10 stens - high score) [8].

\section{Statistical analysis}

Data are shown as means and standard deviations and are analysed with student $t$-test and Anova. Correlations were tested with Pearson correlation test, where $p<0.05$ was considered statistically significant. All data were analysed using Stat View (Carry, NC, US) software.

The study was approved by the Ethics Committee of Pomeranian Medical University.

\section{Results}

Primary indications for the LTx procedure and the period after grafting showed no significant relation to post-transplant physical activity assessed with MILTPAQ (data not shown). Leisure time physical activity was significantly lower in females than in males (1804.3 \pm 1848.9 vs. $2619.9 \pm 2067, p=0.03$ ). A younger age at survey and at surgery were significantly associated with a higher activity ( $p=0.02$ and $p=0.03$, respectively) (Table II).

Patients who returned to employment demonstrated a comparable total activity ( $\mathrm{kcal} /$ week) to those who were not working $2338.9 \pm 2024.3$ vs. $2240.7 \pm 2016.7$; $p=0.80$ (Table III).

The $\mathrm{HBI}$ showed a significant correlation between all four domains and both age at transplantation and age at survey. There was also a negative correlation between positive mental attitude and body mass index (BMI). These data are summarised in Table II.

Neither the primary indication for the procedure nor the period after surgery had a significant relationship with $\mathrm{HBI}$ (data not shown). Gender had no effect on $\mathrm{HBI}$ in the analysed groups of patients (data not shown). It was shown that working had a significant effect on the level of health behaviours in nearly all HBI categories (Table III).

Table I. Demographic and clinical data on analysed patients

\begin{tabular}{lc} 
Parameter & Result \\
\hline Total number of patients & 107 \\
\hline $\begin{array}{l}\text { Age at transplantation, mean } \pm \text { SD } \\
\text { (range) [years] }\end{array}$ & $46.7 \pm 11.6(17-63)$ \\
\hline Age at survey, mean \pm SD (range) [years] & $49.9 \pm 11.4(21-67)$ \\
\hline Gender, $n$ (\%) (male/female) & $62(57.9) / 45(42.1)$ \\
\hline Period after transplantation, $n(\%):$ & $21(19.6)$ \\
\hline Group A (6-12 months) & $48(44.9)$ \\
\hline Group B (13-36 months) & $38(35.5)$ \\
\hline Group C (>36 months) & $24(22.4)$ \\
\hline Original diagnosis, $n$ (\%): & $15(14.0)$ \\
\hline Alcohol liver disease & $33(30.9)$ \\
\hline \begin{tabular}{l} 
Viral \\
\hline Autoimmune/cholestatic
\end{tabular} & $35(32.7)$ \\
\hline Other & \\
\hline
\end{tabular}

Group A - 6 months to 12 months after liver transplantation, group B - from 13 months to 36 months after liver transplantation, group C - more than 36 months after liver transplantation. One hundred and five (61 male/44 female) post-transplant patients have given valuable answers in the Minnesota Leisure Time Physical Activity Questionnaire (MILTPAQ). 
Table II. Correlation between the selected factors and analysed questionnaires

\begin{tabular}{|c|c|c|c|c|c|}
\hline Variable & Age at transplantation & Age at survey & $\begin{array}{l}\text { The period after } \\
\text { transplantation }\end{array}$ & $\begin{array}{l}\text { Body mass } \\
\text { index }\end{array}$ & Weight \\
\hline \multicolumn{6}{|l|}{ MILTPAQ: } \\
\hline $\begin{array}{l}\text { Total activity kcal/ } \\
\text { week }\end{array}$ & $\begin{array}{c}r=-0.2 \\
(p=0.03)\end{array}$ & $\begin{array}{l}r=-0.22 \\
(p=0.02)\end{array}$ & $\begin{array}{l}r=-0.04 \\
(p=0.65)\end{array}$ & $\begin{array}{l}r=-0.17 \\
(p=0.1)\end{array}$ & $\begin{array}{l}r=-0.07 \\
(p=0.42)\end{array}$ \\
\hline \multicolumn{6}{|l|}{ HBI: } \\
\hline Health behaviours & $\begin{array}{c}r=0.34 \\
(p=0.0003)\end{array}$ & $\begin{array}{c}r=0.36 \\
(p=0.0001)\end{array}$ & $\begin{array}{c}r=0.07 \\
(p=0.47)\end{array}$ & $\begin{array}{c}r=0.12 \\
(p=0.18)\end{array}$ & $\begin{array}{c}r=0.32 \\
(p=0.74)\end{array}$ \\
\hline Proper dietary habits & $\begin{array}{c}r=0.29 \\
(p=0.002)\end{array}$ & $\begin{array}{c}r=0.30 \\
(p=0.001)\end{array}$ & $\begin{array}{c}r=0.02 \\
(p=0.81)\end{array}$ & $\begin{array}{l}r=0.06 \\
(p=0.52)\end{array}$ & $\begin{array}{c}r=-0.02 \\
(p=0.8)\end{array}$ \\
\hline $\begin{array}{l}\text { Preventive } \\
\text { behaviours }\end{array}$ & $\begin{array}{c}r=0.23 \\
(p=0.01)\end{array}$ & $\begin{array}{c}r=0.26 \\
(p=0.005)\end{array}$ & $\begin{array}{c}r=0.10 \\
(p=0.33)\end{array}$ & $\begin{array}{c}r=0.10 \\
(p=0.29)\end{array}$ & $\begin{array}{c}r=0.04 \\
(p=0.64)\end{array}$ \\
\hline $\begin{array}{l}\text { Positive mental } \\
\text { attitude }\end{array}$ & $\begin{array}{l}r=0.30 \\
(p=0.01)\end{array}$ & $\begin{array}{c}r=0.26 \\
(p=0.005)\end{array}$ & $\begin{aligned} r & =0.10 \\
(p & =0.29)\end{aligned}$ & $\begin{array}{c}r=0.20 \\
(p=0.03)\end{array}$ & $\begin{array}{c}r=0.11 \\
(p=0.25)\end{array}$ \\
\hline Health practices & $\begin{array}{c}r=0.32 \\
(p=0.001)\end{array}$ & $\begin{array}{c}r=0.31 \\
(p=0.001)\end{array}$ & $\begin{aligned} r & =0.14 \\
(p & =0.88)\end{aligned}$ & $\begin{array}{c}r=0.05 \\
(p=0.54)\end{array}$ & $\begin{array}{l}r=-0.01 \\
(p=0.92)\end{array}$ \\
\hline Sten & $\begin{array}{c}r=0.70 \\
(p=0.0003)\end{array}$ & $\begin{array}{c}r=0.34 \\
(p=0.0003)\end{array}$ & $\begin{array}{c}r=0.07 \\
(p=0.44)\end{array}$ & $\begin{array}{c}r=0.14 \\
(p=0.14)\end{array}$ & $\begin{aligned} r & =0.10 \\
(p & =0.37)\end{aligned}$ \\
\hline
\end{tabular}

MILTPAQ - Minnesota Leisure Time Physical Activity Questionnaire, HBI - Health Behaviour Inventory.

Table III. Professional work and MILTPAQ/HBI in analysed patients

\begin{tabular}{|c|c|c|c|}
\hline Variable & Employed $(n=40)$ & Unemployed $(n=67)$ & Value of $p$ \\
\hline \multicolumn{4}{|l|}{ MILTPAQ: } \\
\hline Total activity kcal/week & $2338.9 \pm 2024.3$ & $2240.7 \pm 2016.7$ & 0.80 \\
\hline \multicolumn{4}{|l|}{$\mathrm{HBI}:$} \\
\hline Health behaviours & $92.9 \pm 11.5$ & $100.5 \pm 11.5$ & 0.001 \\
\hline Proper dietary habits & $3.7 \pm 0.8$ & $3.9 \pm 0.6$ & 0.13 \\
\hline Preventive behaviours & $4.2 \pm 0.5$ & $4.4 \pm 0.5$ & 0.03 \\
\hline Positive mental attitude & $3.9 \pm 0.6$ & $4.2 \pm 0.6$ & 0.03 \\
\hline Health practices & $3.6 \pm 0.5$ & $4.2 \pm 0.5$ & 0.001 \\
\hline Sten & $7.2 \pm 1.5$ & $8 \pm 1.5$ & 0.01 \\
\hline
\end{tabular}

All values are shown as mean \pm SD. MILTPAQ - Minnesota Leisure Time Physical Activity Questionnaire, HBI - Health Behaviour Inventory.

\section{Discussion}

Organ transplantation has become increasingly important in the life-saving treatment of various diseases, and annually over 35,000 transplants of vital organs are carried out worldwide. There is also a growing body of evidence on the crucial role of exercise in the quality of life of transplant recipients - most studies show that exercise results in improved endurance and strength capacity in almost all groups of transplant recipients. With some precautions, organ transplant recipients can exercise and obtain effects similar to those achieved in the healthy population of similar age [12].
The role of physical exercise for the proper functioning of the human body is obvious and indisputable. Physical activities can be divided into those associated with occupation and those undertaken only in leisure time, which requires adopting a healthy lifestyle. Many studies clearly show that regular physical activity in leisure time plays an important role in reducing risk factors and mortality rates [13]. In addition, physical activity has been shown to exert a beneficial effect on long-term recovery after major surgical operations, including LTx [14].

The relationship between physical activity and graft outcome makes sense in light of other related research 
on the impact of physical activity on health. Physical activity leads to improved cardiovascular function, which probably improves perfusion and oxygen delivery to a kidney graft, and may also delay development of atherosclerosis, the primary cause of death among kidney transplant recipients $[15,16]$. A similar trend has been observed in lung recipients, showing that regular physical exercise has a positive effect and facilitates a faster return to active life after transplantation [17]. Also, recipients of a heart transplant note the benefits of moderate exercise, showing that regular exercise improves physical health and mental health [18]. Extensive research has also been carried out in the area of the relation between physical activity and cancer. Numerous reviews of epidemiological and randomised controlled trials have confirmed an inverse relationship between physical activity and the incidence of cancer [19].

In our study we not only evaluated physical activity in leisure time, but we also applied HBI, which can assist in the programming of preventive measures, determining the direction of behaviour changes and monitoring changes in health-related practices. Previous studies with $\mathrm{HBI}$ have indicated its value in differentiating between categories of health-supporting and health-endangering behaviours, particularly in patients after severe surgical procedures. Importantly, despite the patients' knowledge regarding the need for proper health behaviours, most of them have problems in complying with the recommendations, particularly in their own daily life [8]. In our study, the physical activity of women after LTx assessed with Minnesota Leisure Time Physical Activity Questionnaire was significantly lower than in male patients. We also observed this trend in our previous work, in which another questionnaire (IPAQ) showed significantly lower physical activity in female patients compared to men [20]. A similar trend was observed in another study on heart recipients, where the surveyed men showed greater activity compared to women [21]. This confirms a pattern of physical activity observed in studies conducted in America and Europe. In many works, men had a higher level of activity in all age groups. This is due to the fact that men undertake regular exercise more often and more spontaneously [22, 23].

A higher physical activity among younger patients after LTx was also reported [24]. Returning to work after LTx was not related to the level of physical activity in leisure time, perhaps due to a lack of time for systematic physical activity. However, our other study does not support this notion; we showed that patients who returned to work after LTx had significantly better health-related quality of life in most SF-36 domains, and a higher level of physical activity compared to those not working [20].
This could be related to the fact that the evaluation of physical activity was based on the IPAQ questionnaire, which includes physical activity associated with work and leisure time [20]. Similar results were obtained by Slattery et al., who demonstrated that working male patients with ischaemic heart disease had higher levels of moderate physical activity in MILTPAQ [25]. Other studies show that all candidates for transplantation typically have an impaired physical performance level that not only interferes with their ability to perform leisure time exercise, but often also limits their ability to perform even simple physical tasks such as climbing stairs [26]. After receiving a donor organ these patients report improved quality of life and are frequently able to successfully return to work [27]. While analysing the impact of work, age, and BMI of patients after LTX on health behaviour, a significant correlation was observed in almost all categories of health behaviour.

\section{Conclusions}

Patients' gender exerts a significant effect on the reported level of physical activity. Leaner and younger patients were more active according to MILTPAQ and had better indicators of health behaviour. The primary indications and time after transplantation had no significant relationship with the level of physical activity undertaken by patients after LTx or their health behaviours. Employment after surgery showed a significant correlation with $\mathrm{HBI}$, but showed no relationship to the level of physical activity of individuals. This study confirms the benefits of regular physical activity and the need for proper health behaviours after LTx, as necessary complements to pharmacological treatment that assists in the return to an active life.

\section{Acknowledgments}

Ewa Wunsch was supported by the Foundation for Polish Science.

\section{Conflict of interest}

The authors declare no conflict of interest.

\section{References}

1. Hellgren A, Berglund B, Gunnarsson U, et al. Health-related quality of life after liver transplantation. Liver Transpl Surg 1998; 4: 215-1.

2. Hunt CM, Tart JS, Dowdy E, et al. Effect of orthotopic liver transplantation on employment and health status. Liver Transpl Surg 1996; 2: 148-3.

3. Dew MA, Switzer GE, Goycoolea JM, et al. Does transplantation produce quality of life benefits? Transplantation 1997; 64: 1261-3. 
4. Nicholas JJ, Oleske D, Robinson LR, et al. The quality of life af ter orthotropic liver transplantation: an analysis of 166 cases. Arch Phys Med Rehabil 1994; 75: 431-5.

5. Hicks FD, Larson JL, Ferrans CE. Quality of life after liver transplant. Res Nurs Health 1992; 15: 111-9.

6. Foley TC, Davis CP, Conway PA. Liver transplant recipients self-report of symptom frequency, symptom distress, quality of life. Transplant Proc 1989; 21: 2417-8.

7. Pereira MA, Fitz Gerald SJ, Gregg EW, et al. A Collection of physical Activity Questionnaires for health-related research. Med Sci Sports Ex 1997; 29: 6-10.

8. Kawalec E, Reczek A, Porębska A, et al. Health behaviours of obese and overweight patients. Nursing in XXI Century 2011; 2: 27-3.

9. Walentukiewicz A, tysak A, Wilk B. Determinants of health in 18-year-old girls in Gdańsk - health behaviors. Probl Hig Epidemiol 2011; 92: 482-5.

10. Jurkiewicz M, Mianowana W, Wysokiński A. Physical activity as a behaviour decreasing the risk of a recurrence of coronary events in patients after myocardial infarction. Pol J Cardio 2011; 13: 24-30.

11. Bojar I, Humeniuk E, Wdowiak L, et al. Dietary behaviors of pregnant women. Probl Hig Epidemiol 2007; 88: 74-7.

12. Kjaer M, Beyer N, Secher NH. Exercise and organ transplantation. Scand J Med Sci Sports 1999; 1: 1-14.

13. Nowak Z. Prospective evaluation of the usefulness of physical activity of patients after coronary intervention. AWF, Katowice 2006.

14. Payne JL, McCarty KR, Drougas JG, et al. Outcomes analysis for 50 liver trans plant recipients: the Vanderbilt experience. Am Surg 1996; 62:320-5.

15. Shirali AC, Bia MJ. Management of cardiovascular disease in renal transplant recipients. Clin J Am Soc Nephrol 2008; 3: 491-8.

16. Painter PL, Hector L, Ray K, et al. Effects of exercise training on coronary heart disease risk factors in kidney transplant recipients. Am J Kidney Dis 2003; 42: 362-9.

17. Wickerson L. Exercise training following lung transplant is now evidence-based practice. J Physiotherapy 2013; 59: 58-3.

18. Spaderna H, Zahn D, Schulze Schleithoff S, et al. Depression and disease severity as correlates of everyday physical activity in heart transplant candidates. Transplant Int 2010; 23: 813-2.

19. Kruk J, Czerniak U. Physical activity and its relation to cancer risk: updating the evidence. Asian Pac J Cancer Prev 2013; 14: 3993-3.

20. Kotarska K, Wunsch E, Kempińska-Podhorodecka A, et al. Factors affecting health-related quality of life and physical activity after liver transplantation for autoimmune and non-autoimmune liver diseases: a prospective, single centre study. J Immunol Res 2014; 1: 1-9.

21. Trost SG, Owen N, Bauman AE, et al. Correlates of adults' participation in physical activity: review and update. Med Sci Sports Exerc 2002; 34: 1996-9.

22. Malina RM, Bouchard C, Bar-Or O. Growth, maturation, and physical activity. Human Kinetics, Champaign, IL, 2004

23. Ainsworth BE. Issues in the assessment of physical activity in women. Res Q Exerc Sport 2000; 71 (2 Suppl.): S37-42.
24. Nowak Z, Plewa M, Skowron M, et al. Minnesota leisure time physical activity questionnaire as an additional tool in clinical assessment of patients undergoing percutaneous coronary interventions. J Hum Kinet 2010; 23: 79-87.

25. Slattery ML, Jacobs DR, Nichaman JR, et al. Leisure time physical activity and coronary heart disease death. The US Railroad Study. Circulation 1989; 79: 304-1.

26. Badenhop DT. The therapeutic role of exercise in patients with orthopic heart transplant. Med Sci Sports Ex 1995; 27: 975-5.

27. Tarter RE, Switala JA, Arria A, et al. Quality of life before and after orthotopic hepatic transplantation. Arch Intern Med 1991; 151: 1521-6.

Received: 30.09.2014

Accepted: 21.10 .2014 